This is an author produced version of a paper published in European Journal of Neuroscience. This paper has been peer-reviewed but does not include the final publisher proof-corrections or journal pagination.

Citation for the published paper:

Ericson C, Georgievska B, Lundberg C.

"Ex vivo gene delivery of GDNF using primary astrocytes transduced with a lentiviral vector provides neuroprotection in a rat model of Parkinson's disease."

European Journal of Neuroscience, 2005, Vol: 22, Issue: 11, pp. 2755-64. http://dx.doi.org/10.1111/j.1460-9568.2005.04503.x

Access to the published version may require journal subscription.

Published with permission from: Blackwell Synergy 


\section{EX VIVO GENE DELIVERY OF GDNF USING PRIMARY ASTROCYTES TRANSDUCED WITH A LENTIVIRAL VECTOR PROVIDES NEUROPROTECTION IN A RAT MODEL OF PARKINSON'S DISEASE}

Cecilia Ericson, Biljana Georgievska* and Cecilia Lundberg*†

Wallenberg Neuroscience Center, BMC A11, 22184 Lund, Sweden

Fax number: +46-46-2220561

*These two authors contributed equally to this work.

†Corresponding author: Email address: Cecilia.Lundberg@mphy.lu.se

Running title: Neuroprotection by GDNF-transduced astrocytes

Number of pages: 30

Number of figures: 5

Total number of words in: (i) the whole manuscript:

(ii) the Abstract: 248

(iii) the Introduction: 496

Keywords: 6-hydroxydopamine, dopamine, gene therapy, GFP, glial cell line-derived neurotrophic factor, glial cells, transplantation, tyrosine hydroxylase 


\section{Abstract}

Astrocytes are, as normal constituents of the brain, promising vehicles for ex vivo gene delivery to the central nervous system. In the present study, we have used a lentiviral vector encoding glial cell line-derived neurotrophic factor (GDNF) to transduce ratderived primary astrocytes, in order to evaluate their potential for long-term transgene expression in vivo and neuroprotection in a rat model of Parkinson's disease. Following transplantation of GDNF-transduced astrocytes to the intact striatum, the level of released GDNF was $2.93 \pm 0.28 \mathrm{ng} / \mathrm{mg}$ tissue at 1 week post-grafting, reduced to $0.42 \pm 0.12 \mathrm{ng} / \mathrm{mg}$ tissue at 4 weeks, however, was maintained at this level throughout the experiment (12 weeks; $0.53 \pm 0.068 \mathrm{ng} / \mathrm{mg}$ tissue). Similarly, grafting to the substantia nigra (SN) resulted in a significant overexpression of GDNF $(\sim 0.20 \mathrm{ng} / \mathrm{mg}$ tissue) at 1 week. Intact animals receiving transplants of GDNF-transduced astrocytes displayed an increased contralateral turning $(5.39 \pm 1.19$ turns/min) in the amphetamineinduced rotation test, which significantly correlated with the GDNF tissue levels measured in the striatum, indicating a stimulatory effect of GDNF on the dopaminergic function. Transplantation of GDNF-transduced astrocytes to the SN one week prior to an intrastriatal 6-hydroxydopamine lesion provided a significant protection of nigral tyrosine hydroxylase-positive cells. By contrast, when the cells were transplanted to the striatum, the level of released GDNF was not sufficient to rescue the striatal fibers and, hence, protect the nigral dopaminergic neurons. Overall, our results suggest that genetically modified astrocytes expressing GDNF can provide neuroprotection in a rat model of Parkinson's disease following transplantation to the SN. 


\section{Introduction}

Parkinson's disease (PD) is characterized by a progressive degeneration of dopaminergic (DA) neurons in the substantia nigra (SN), giving rise to symptoms such as resting tremor, bradykinesia, rigidity and postural abnormalities (Duvoisin, 1992). The most common treatment for PD patients is oral intake of levo-dopa, a DA precursor that crosses the blood-brain barrier, however, the efficacy of this drug treatment is reduced over time. Therefore, new strategies aimed at either protecting the remaining DA neurons or restoring DA neurotransmission in the striatum are being developed. One approach towards protecting the DA neurons and their axonal projections is the use of neurotrophic factors, in particular glial cell line-derived neurotrophic factor (GDNF). Since the discovery in 1993 (Lin et al., 1993), many studies have demonstrated survival-promoting effects of GDNF on DA neurons in various rodent and primate models of PD (Gash et al., 1998; Kordower et al., 2000; Kirik et al., 2004). The incapability of GDNF to cross the blood-brain-barrier requires direct administration of the factor into the brain. This can be accomplished by (i) direct injection of the recombinant protein (Winkler et al., 1996; Lapchak et al., 1997; Kirik et al., 2000a; Rosenblad et al., 2000b), (ii) in vivo GDNF gene delivery using viral vectors (Choi-Lundberg et al., 1997; Mandel et al., 1997; Bohn et al., 1999; Kirik et al., 2000b; Kordower et al., 2000; Georgievska et al., 2002b), or (iii) transplantation of cells modified in vitro to express GDNF (ex vivo gene transfer; Perez-Navarro et al., 1999; Cunningham \& Su, 2002; Duan et al., 2004). Currently, the most effective delivery systems for long-term and stable expression of GDNF in the brain are based on lentiviral (Deglon et al., 2000; Kordower et al., 2000; Georgievska et al., 2002a; Georgievska et al., 2002b) and adeno-associated viral vectors (McCown et al., 1996; 
Mandel et al., 1997; Kirik et al., 2000b; Mandel, 2000). However, since these viral vectors mainly transduce neurons, GDNF is not only produced and released at the injection site, but also transported to other regions of the brain. Thus, a major advantage with the ex vivo gene transfer model is the possibility to obtain a local delivery of GDNF at the site of transplantation. In addition, the genetically engineered cells can be expanded in vitro and evaluated for toxicity and level of protein expression prior to transplantation (Lundberg, 1999).

We have previously shown that embryonic rat-derived astrocytes transduced with a lentiviral vector encoding green fluorescent protein (GFP) have great potential for use in ex vivo gene therapy to the rat striatum (Englund et al., 2000; Ericson et al., 2002). The astrocytes survived well following transplantation and a stable, albeit small, fraction of the cells $(\sim 1 \%)$ expressed GFP for at least 6 weeks (Ericson et al., 2002). The present study was therefore designed to evaluate the potential of primary astrocytes, transduced in vitro using a GDNF-encoding lentiviral vector, for (i) longterm transgene expression in vivo, and (ii) providing protection of nigrostriatal DA neurons in 6-hydroxydopamine (6-OHDA) lesioned rats. 


\section{Material and methods}

\section{Preparation of astrocyte cultures}

Primary astrocyte cultures were prepared from the lateral ganglionic eminence (LGE) of 15-day-old rat embryos. The embryos were removed from pregnant Sprague-Dawley rats (B\&K Universal, Stockholm, Sweden) under deep anesthesia using sodium pentobarbital (240 mg/kg; Apoteksbolaget, Sweden), placed in Dulbecco's Modified essential medium (DMEM; Gibco, Sweden) and LGE was dissected out bilaterally as previously described (Olsson et al., 1995). The LGE-pieces (on average 16-24 pieces) were then placed in a $0,05 \%$ DNase $/ 0,1 \%$ trypsin solution in DMEM for 20 min at $37^{\circ} \mathrm{C}$. Following three rinses in DMEM/DNase, the tissue pieces were mechanically dissociated and centrifuged for $5 \mathrm{~min}$ at $600 \mathrm{rpm}$. The cell pellet was resuspended and seeded out into one uncoated T75 flask $\left(75 \mathrm{~cm}^{2}\right.$; NUNC, Denmark) and fed in DMEM/F12 (Gibco, Sweden), supplemented with $\mathrm{NaHCO}_{3}$ (13 mM; Sigma, Sweden), HEPES (5 mM; Sigma, Sweden), glucose (0,6\%; Sigma, Sweden) glutamine (2 mM; Sigma, Sweden), 10\% fetal bovine serum (FBS; Sigma, Sweden), epidermal growth factor (20 ng/ml, human recombinant; R\&D Systems, UK) and a defined hormone and salt mixture including $20 \mu \mathrm{g} / \mathrm{ml}$ insulin, $100 \mu \mathrm{g} / \mathrm{ml}$ transferrin, $20 \mathrm{nM}$ progesterone, 60 $\mu \mathrm{M}$ putrescine and $30 \mathrm{nM}$ sodium selenite (all from Sigma, Sweden). At about 1 week after plating, the cells had grown to confluency and were passaged once (1:2) before being frozen down $\left(\right.$ at $\left.-150^{\circ} \mathrm{C}\right)$. The cells were subsequently thawed and used for further experiments (see below).

\section{Construction of lentiviral vectors}

The plasmids used for the self-inactivated (SIN; Zufferey et al., 1998) lentiviral (LV) vector production (pHR'CMV-GFP-WHV, pMD.G and pCMVDR8.91; Zufferey et al., 
1997) were kindly provided by Dr. Didier Trono (University of Geneva Medical School, Geneva, Switzerland). The construction of pHR'CMV-GDNF has been described previously (Rosenblad et al., 2000a).

\section{Production of lentiviral vectors}

The LV vectors were produced as previously described (Zufferey et al., 1997). Briefly, the transfer plasmids pHR'CMV-GFP/GDNF-WHV were co-transfected with pMD.G and pCMVDR8.91 into $293 \mathrm{~T}$ cells. The supernatant was collected 2 and 3 days after transfection and concentrated by two rounds of ultracentrifugation at $141,000 \mathrm{~g}$ for 1.5 hrs and the final pellet was dissolved in DMEM containing 10\% FBS. The number of transducing units (TU) for the LV-CMV-GFP vector was determined by infecting $100,000293 \mathrm{~T}$ cells using a serial dilution of the vector. The dilution resulting in less then 30\% GFP-positive cells was used to calculate the number of TU per ml. The particle titer for both the LV-CMV-GFP and LV-CMV-GDNF vectors was estimated by an RNA slot blot hybridization technique (von Schwedler et al., 1993). The ratio between the number of TU and the particle titer for the LV-CMV-GFP vector was used to estimate the number of TU for the LV-CMV-GDNF vector.

\section{Infection of cultured astrocytes}

A multiple of infection of 5 was used to infect the astrocytes at passage 2 or 3 . The cells were transduced with the respective LV vectors (LV-CMV-GFP or LV-CMVGDNF) in T75 flasks ( $10^{6}$ cells/flask) 48 hrs prior to grafting. Astrocytes transplanted to animals processed for immunohistochemistry were pre-labeled with ${ }^{3} \mathrm{H}$-thymidine (1 $\mu \mathrm{Ci} / \mathrm{ml}$, Amersham, Sweden) every second day, starting 7 days prior to transplantation. After three washes and trypsination, the astrocytes were centrifuged for 5 min at 600 
rpm and the cell pellet was resuspended in Hank's Balanced Salt Solution (HBSS; Gibco, Sweden). The cell number was estimated in a hemocytometer and prepared into a single cell suspension with a density of 50.000 cells/ $\mu 1$ in HBSS.

\section{Surgical procedures}

A total of 90 adult female Sprague-Dawley rats (B\&K Universal, Stockholm, Sweden) were housed three per cage with free access to food and water under a 12 hour light:dark cycle. All surgical procedures were approved by and performed according to the guidelines of the Ethical Committee for Use of Laboratory Animals at Lund University, Sweden. The animals were anaesthetized with halothane $\left(2 \%\right.$ in $\left.\mathrm{O}_{2}\right)$ and placed into a stereotaxic frame (Kopf Instruments, Tujunga, CA, USA).

Long-term GDNF expression study: For determination of GDNF release in vivo in intact animals at different time-points, 300,000 GFP- or GDNF-transduced cells were grafted unilaterally into three sites $(100,000$ cells/site) in the striatum (GFP-Str, $n=8$; GDNF-Str, $\mathrm{n}=23$ ) and 200,000 cells were injected into two sites in the SN (GFP-SN, $\mathrm{n}=6$; GDNF-SN, $\mathrm{n}=11$ ) using a $10 \mu 1$ Hamilton syringe. The striatal injections were done at the following coordinates, as calculated from the bregma (Paxinos \& Watson, 1986): anterior-posterior $(\mathrm{AP})=+1.4 ;+0.4 ;-0.8$, medial-lateral $(\mathrm{ML})=-2.6 ;-3.4 ;-4.4$, and dorso-ventral $(\mathrm{DV})=-5.0$ and -4.0 , with the tooth bar $(\mathrm{TB})$ set at $0.0 \mathrm{~mm}$. The nigral coordinates were as follows: $\mathrm{AP}=-4.8 ;-5.6, \mathrm{ML}=-2.0$, and $\mathrm{DV}=-7.0$, with the TB set at $-2.3 \mathrm{~mm}$.

6-OHDA lesion study: To study the ability of GDNF-transduced astrocytes to provide neuroprotection, animals received either 300,000 cells in the striatum or 200,000 cells in the SN (at the same coordinates as above) followed one week later by unilateral injections of either $7 \mu \mathrm{g}$ or $21 \mu \mathrm{g}$ of 6-OHDA (calculated as free base and dissolved in 
0.05\% ascorbate acid-supplemented saline; Sigma, St. Louis, MO). For groups receiving the $7 \mu$ g lesion (GFP-Str, $n=5$; GDNF-Str, n=5; GFP-SN, n=5; GDNF-SN, $\mathrm{n}=5) 2 \mu \mathrm{l}$ of 6-OHDA $(3.5 \mu \mathrm{g}$ free-base/ $\mu \mathrm{l})$ was injected into one site in the striatum at the following coordinates: $\mathrm{AP}=+1.0 ; \mathrm{ML}=-3.0 ; \mathrm{DV}=-5.0$ and $\mathrm{TB}=0.0$. Animals assigned to the $21 \mu \mathrm{g}$ lesion groups (GFP-Str, $\mathrm{n}=5$; GDNF-Str, $\mathrm{n}=6$; GFP-SN, $\mathrm{n}=5$; GDNF-SN, $\mathrm{n}=6$ ) received a total of $21 \mu \mathrm{g}$ 6-OHDA, divided into three $7 \mu \mathrm{g}$ deposits (2 $\mu 16-\mathrm{OHDA} / \mathrm{site})$ in the right striatum at the following coordinates: $\mathrm{AP}=+1.0 ;-0.1 ;-1.2$, $\mathrm{ML}=-3.0 ;-3.7 ;-4.5$, and $\mathrm{DV}=-5.0$, with the $\mathrm{TB}$ set at $0.0 \mathrm{~mm}$. The toxin was injected using a $10 \mu 1$ Hamilton syringe with an attached glass capillary (inner diameter $\sim 60-80$ $\mu \mathrm{m})$ to minimize the tissue damage.

\section{Amphetamine-induced rotation}

The animals were injected with D-amphetamine sulfate $(2.5 \mathrm{mg} / \mathrm{kg}$, i.p., Apoteksbolaget, Sweden) and placed in automated rotometer bowls. Rotational behavior was assessed by monitoring total number of whole body $\left(360^{\circ}\right)$ turns over 90 min. The rotational scores are expressed as net $360^{\circ}$ turns/min and contralateral rotations (i.e. opposite the grafted/lesioned side) were assigned a positive value.

\section{GDNF ELISA}

The GDNF tissue levels in the intact striatum and SN were measured at 1 week (GDNF-Str, n=5; GFP-SN, n=4; GDNF-SN, n=4), 4 weeks (GFP-Str, n=4; GDNF-Str, $\mathrm{n}=5$; GDNF-SN, $\mathrm{n}=3$ ) and 12 weeks (GDNF-Str, $\mathrm{n}=5$ ) post-transplantation. The animals were deeply anesthetized with sodium pentobarbital $(240 \mathrm{mg} / \mathrm{kg}$; Apoteksbolaget, Sweden), decapitated and the brains were quickly removed and placed into a brain slicer. Two coronal slices of $3 \mathrm{~mm}$ and $2 \mathrm{~mm}$ thickness were cut to cover 
the striatum, which was dissected bilaterally, dorsal to the anterior commissure and freed from cortex and septum. The $\mathrm{SN}$ was punched out from a $3 \mathrm{~mm}$ thick $(2 \mathrm{~mm}$ in diameter) slice through the midbrain. The striatal and nigral tissue pieces were later sonicated (Vibra Cell Sonics and Materials Inc., Danbury, CT) in a homogenization buffer $(50 \mathrm{mM}$ Tris, $\mathrm{pH} 7.4,150 \mathrm{mM} \mathrm{NaCl}, 1 \%$ Triton $\mathrm{X}-100,1.7 \mu \mathrm{g} / \mathrm{ml}$ phenylmethylsulfonyl fluoride, $1.0 \mu \mathrm{g} / \mathrm{ml}$ leupeptin, $10 \mu \mathrm{g} / \mathrm{ml}$ aprotinin and $1.0 \mu \mathrm{g} / \mathrm{ml}$ pepstatin A) at a concentration of $30 \mathrm{mg} / \mathrm{ml}$ (wet weight per volume) and centrifuged at $20.000 \mathrm{~g}$ for $10 \mathrm{~min}$ at $4^{\circ} \mathrm{C}$. Tissue levels of GDNF were determined on homogenates by ELISA according to the supplier's recommendations (G3240, Promega, Madison, WI).

\section{Immunohistochemistry}

Histological analyses were performed on a subset of rats from the long-term GDNF expression study at 1 week (GFP-Str, n=2; GDNF-Str, n=4) and 4 weeks (GFP-Str, $\mathrm{n}=2$; GDNF-Str, $\mathrm{n}=4$; GFP-SN, $\mathrm{n}=2$; GDNF-SN, $\mathrm{n}=4$ ) following transplantation, while all animals in the 6-OHDA lesion study were killed at 4 weeks after grafting (i.e. 3 weeks post-lesion). The rats were deeply anaesthetized with sodium pentobarbital (240 $\mathrm{mg} / \mathrm{kg}$, Apoteksbolaget, Sweden) and perfused through the ascending aorta with isotonic saline followed by $250-300 \mathrm{ml}$ of ice-cold 4\% PFA in $0.1 \mathrm{M}$ phosphate buffer (PB), $\mathrm{pH}$ 7.4. The brains were removed and post-fixed for a few hours in the same solution and then transferred to $25 \%$ sucrose in $0.1 \mathrm{M}$ PB before sectioning on a freezing-stage microtome at $40 \mu \mathrm{m}$ in 8 series. Light-field stainings were preformed as previously described (Georgievska et al., 2002a), and the primary antibodies used in this study were chicken-antiGFP (1:5000; Chemicon, Sweden), goat-anti-GDNF (1:2000; R\&D systems, Sweden), mouse-anti-TH (1:2000; Chemicon, Sweden) and 
rabbit-anti-VMAT-2 (1:2000; Chemicon, Sweden). The immunostained sections were mounted on chrome-alum coated slides, dehydrated in ascending alcohol concentrations, cleared in xylene, and coverslipped in DPX. One series of GDNF and GFP immunostained sections were processed for autoradiography to reveal ${ }^{3} \mathrm{H}-$ thymidine labeled cells. After 6 weeks of exposure, the autoradiographs were developed in D-19 (Kodak, Sweden) and coverslipped as described above.

\section{Nigral cell counts}

The total number of TH-positive cells in the SN was estimated by stereology using the optical fractionator (West, 1999). Sampling was performed using the CAST-Grid system (Olympus, Denmark A/S, Aarhus, Denmark), composed of an Olympus BH2 microscope, an X-Y step motor stage run by an IBM-compatible PC computer, and a microcator (Heidnhain, ND 281, Traunreut, Germany). Briefly, the CAST-Grid software (version 2.1.3) was used to delineate the SN pars compacta (SNpc) using the 4x objective. To cover the entire $\mathrm{SN}$, sections displaying the first rostral tip of the SNpc back to the caudal end of the SN pars reticulata (SNpr; 5-6 sections from 1/8 series) were used, as described in detail elsewhere (Georgievska et al., 2002a). In the 100x oil objective a counting frame was placed randomly over the first counting area and was then systematically moved in the X-Y directions until the entire delineated area was sampled.

\section{Striatal fiber density measurements}

The optical densities of TH- and VMAT-2-immunoreactive fibers in the striatum were measured using the NIH 1.63 Image program on a Macintosh computer connected to a digital ProgRes camera (Kontron Elektronik, Germany) and a constant illumination 
table. The striatal fiber density was measured from the entire cross-section of the striatum at three rostocaudal levels corresponding to $\mathrm{AP}=+1.0 ;-0.26 ;-0.92$, relative to bregma and according to the atlas of Paxinos \& Watson, 1986). The optical density readings were corrected for non-specific background by measuring the corpus callosum in each section. The measurements are presented as a percentage of the control (left) side value.

\section{Statistical analysis}

Comparisons of GDNF tissue levels and rotational behavior were made using analysis of variance (ANOVA) and followed by Student-Newman-Keuls post-hoc test when significant (using StatView software; SAS Institute, Cary, NC, USA). Correlation analysis between GDNF tissue levels in the striatum and rotational behavior was performed using simple linear regression. Comparisons of nigral cell counts and striatal densitometry measurements were made using an unpaired $t$-test. For all comparisons, significance was accepted at the $95 \%$ probability level. All values are presented as means \pm S.E.M. 


\section{Results}

We have previously shown that lentivirally transduced rat-derived primary astrocytes survive transplantation to the rat brain well and are able to express the transgene GFP for at least 6 weeks (Ericson et al., 2002). In addition, transduction of the astrocytes with a GDNF-encoding lentiviral vector (LV-CMV-GDNF) resulted in a substantial release of GDNF into the culture media ( $27 \mathrm{ng} \mathrm{GDNF} / 10^{5}$ cells/hour), while no GDNF was detected from the control cultures. In the present study, primary astrocytes transduced with LV-CMV-GDNF in vitro were transplanted into the rat brain in order to evaluate (i) the long-term expression of GDNF in vivo, and (ii) the potential of these cells to protect the nigrostriatal DA neurons when grafted into either the striatum or the SN prior to a mild or severe intrastriatal 6-OHDA lesion.

\section{Long-term GDNF expression in intact animals}

In order to evaluate the long-term transgene expression from LV-transduced (GFP or GDNF) astrocytes in vivo, 200,000 cells were grafted into the SN and 300,000 cells into the striatum in separate groups of intact animals. Following transplantation of GDNF-transduced astrocytes to the SN, the level of GDNF expressed at 1 week was $0.196 \pm 0.053 \mathrm{ng} / \mathrm{mg}$ tissue, which was significantly higher compared to control animals $(0.007 \pm 0.00024 \mathrm{ng} / \mathrm{mg}$ tissue; $P<0.0001 ;$ Fig. $1 \mathrm{~A})$. The expression level reduced at 4 weeks to $0.057 \pm 0.014 \mathrm{ng} / \mathrm{mg}$ tissue, but was still significantly higher than the control group $(P<0.05)$. The GDNF tissue levels represented in the control groups are an average of animals receiving grafts of GFP-transduced astrocytes, and the non-injected contralateral side of animals receiving GDNF-transduced astrocytes, as these were not statistically different from each other $(\mathrm{SN}$ : $[\mathrm{F}(1,12)=2.071 ; \mathrm{P}=0.175]$; striatum: $[F(1,15)=0.246 ; \mathrm{P}=0.627])$. Transplantation of GDNF-transduced astrocytes to the 
striatum resulted in high expression levels of GDNF at 1 week post-grafting $(2.93 \pm 0.28$ $\mathrm{ng} / \mathrm{mg}$ tissue), which were significantly higher compared to the control group $(0.026 \pm 0.01 \mathrm{ng} / \mathrm{mg}$ tissue; $P<0.0001$; Fig. 1B). The GDNF expression level decreased at 4 weeks to $0.42 \pm 0.12 \mathrm{ng} / \mathrm{mg}$ tissue, however, this level was maintained at 12 weeks post-grafting $(0.53 \pm 0.068 \mathrm{ng} / \mathrm{mg}$ tissue $)$, still significantly higher than the control group $(P<0.01)$. The average level of GDNF measured in the right $\mathrm{SN}$ after transplantation to the right striatum was $0.007 \mathrm{ng} / \mathrm{mg}$ tissue, while the average level of GDNF found in the right striatum after nigral transplantation was $0.022 \mathrm{ng} / \mathrm{mg}$ tissue, suggesting that there were no detectable levels of retrograde or anterograde transport of GDNF in host neurons.

Autoradiography for thymidine labeled cells revealed that the transplanted cells were well integrated within the parenchyma, with no signs of host tissue damage, and that the migration was confined within the striatum and extended approximately $1 \mathrm{~mm}$ from the graft core (data not shown). This is in keeping with earlier reports (Englund et al., 2000; Ericson et al., 2002). However, in some animals receiving striatal transplants, the most caudally placed graft had somewhat extended to the neighboring globus pallidus (GP). In the midbrain, the grafted astrocytes had also migrated away from the injection site, but to a lesser extent (approximately $0.5 \mathrm{~mm}$ from graft core) as compared to cells transplanted into the striatum. Protein expression was also evaluated by immunohistochemistry for GFP and GDNF at 1 and 4 weeks post-transplantation, as presented in Fig. 2. At 4 weeks after transplantation to the SN, GFP-expressing astrocytes were found on the border of the SNpc, while released GDNF covered the dorsal part of the same region (Fig. 2A-B). Following transplantation to the striatum, GFP was only detected in cells found in the graft core and a decrease in protein expression was observed from 1 to 4 weeks post-grafting (Fig. 2C-D). In contrast to 
GFP, GDNF is a secreted protein and was thus detected in a widespread area throughout the striatum at 1 week post-transplantation, however, the distribution of GDNF in the striatum was reduced by 4 weeks (Fig. 2E-F), in accordance with the GDNF tissue levels measured by ELISA at the same time-point (see above, Fig. 1B).

\section{Behavioral effects of GDNF overexpression in the striatum of intact animals}

Transplantation of GDNF-transduced astrocytes to the intact striatum induced a significant $\quad(P<0.001) \quad$ contralateral amphetamine-induced turning $\quad(5.39 \pm 1.19$ turns/min) at 1 week following transplantation, compared to control groups receiving GFP-transduced astrocytes $(0.09 \pm 0.95$ turns/min; Fig. 1C), indicating a stimulatory effect on the dopaminergic system on the transplanted side. The contralateral turning bias observed in the GDNF group subsequently decreased at the later time-points and reached to about $0.54 \pm 0.32$ turns/min at 12 weeks, and was no longer significantly different from the control group. The decrease in the turning rate over time was in line with the reduction in GDNF expression from the grafted astrocytes between 1 week (2.93 ng) and 12 weeks (0.53 ng). In fact, the amphetamine-induced turning rate correlated significantly with the GDNF tissue levels in the striatum, as measured at 1, 4 and 12 weeks post-grafting (linear regression, $R=0.825, P<0.0001$; Fig. 1D).

\section{Neuroprotection following transplantation of GDNF expressing astrocytes}

Based on the promising results from the first study, i.e. that GDNF-transduced astrocytes are able to produce and secrete significant levels of GDNF in vivo (see above), we designed a second study to evaluate whether the level of expression and mode of delivery would be able to provide neuroprotection in a rat model of PD. For this purpose, GFP- or GDNF-transduced astrocytes were transplanted to either the 
striatum or the SN, followed 1 week later by an intrastriatal 6-OHDA lesion (7 or 21 $\mu \mathrm{g})$. At 1 week after transplantation, and at the time of lesion, we observed the highest level of GDNF expression (2.93 $\mathrm{ng}$ in the striatum and $0.19 \mathrm{ng}$ in the SN) from the LVtransduced astrocytes, as determined in the first study (see above).

Stereological estimations of the TH-positive cells in the SN at 3 weeks postlesion demonstrated a 40-60\% (7 $\mu$ g 6-OHDA) and 80-90\% (21 $\mu \mathrm{g}$ 6-OHDA) cell loss in animals receiving control (GFP-transduced) grafts into either the striatum or the SN (Fig. 3A-C, D and G). In both lesion models, a significant protection of nigral DA neurons was observed after intranigral transplantation of GDNF-expressing cells (Fig. 3D). In animals receiving the $7 \mu \mathrm{g}$ lesion, transplantation of GDNF-transduced astrocytes to the SN resulted in a 2-fold protection of the TH-positive cells, compared to the control grafted group $(80.0 \pm 15.0 \%$ vs. $37.0 \pm 2.8 \%$ of intact side; Fig. 3D, compare $\mathrm{B}$ and $\mathrm{E})$. In animals receiving the $21 \mu \mathrm{g}$ lesion, the GDNF-transduced astrocytes transplanted to the SN provided a 5-fold protection of TH-positive cells, compared to the control grafted group $(33.0 \pm 5.7 .0 \%$ vs. $9.0 \pm 0.7 \%$ of intact side; Fig. 3D, compare $\mathrm{C}$ and $\mathrm{F}$ ). Intrastriatal GDNF transplants, on the other hand, failed to protect the nigral DA neurons in either lesion model (7 $\mu \mathrm{g}$ lesion: GFP-Str, $55.6 \pm 7.4 \%$ of intact side; GDNF-Str, $65.6 \pm 12.3 \%$ of intact side; $21 \mu \mathrm{g}$ lesion: GFP-Str, $12.0 \pm 1.6 \%$ of intact side; GDNF-Str, $16.5 \pm 1.3 \%$ of intact side; Fig. 3G-I).

All 6-OHDA lesioned animals were also tested for amphetamine-induced rotational behavior at 3 weeks after the 6-OHDA lesion and prior to sacrifice. Transplantation of GDNF-transduced astrocytes to the striatum followed by a $7 \mu \mathrm{g}$ lesion resulted in a significant difference in rotational behavior compared to the control group (GDNF-Str, 2.8 \pm 1.0 turns/min; GFP-Str, $7.4 \pm 1.7$ turns/min; $P<0.05$ ). This was not observed when the GDNF-expressing astrocytes were transplanted to the SN 
(GDNF-SN, $13.5 \pm 5.6$ turns/min; GFP-SN, $16.3 \pm 1.4$ turns/min; $P>0.05$ ). In the $21 \mu \mathrm{g}$ lesion groups, no significant difference was observed between any of the groups (GDNF-Str, 9.7 \pm 2.7 turns/min; GFP-Str, 17.0 \pm 3.6 turns/min; $P>0.05 ;$ GDNF-SN, 15.6 \pm 3.4 turns/min; GFP-SN, $18.4 \pm 1.3$ turns/min; $P>0.05)$.

We have in previous studies observed that a continuous overexpression of GDNF (using viral vectors) induces a down-regulation of $\mathrm{TH}$ in both the intact and lesioned striatum (Georgievska et al., 2002a,2004). The extent of striatal denervation following intrastriatal injections of 7 or $21 \mu \mathrm{g}$ 6-OHDA was therefore assessed by measuring both TH- and VMAT-2-positive fiber densities in the striatum in order to rule out a potential down-regulation of TH by GDNF. In animals receiving GFPtransduced astrocytes into either the SN or the striatum, the TH-positive fiber density in the $7 \mu \mathrm{g}$ lesion groups was determined to about $19.9-41 \%$ of intact side, and in the 21 $\mu \mathrm{g}$ lesion groups to about $10.4-16.6 \%$ of intact side (Fig. 4A). Similarly, the VMAT-2positive fiber densities in the control groups were measured to about $37.7-55.1 \%$ of intact side in the $7 \mu \mathrm{g}$ lesion group, and to about $22.2-30.8 \%$ of intact side in the $21 \mu \mathrm{g}$ lesion groups (Fig. 4B). Groups receiving GDNF-transduced astrocytes into either the SN or the striatum were not significantly different from the control groups on either measure (TH or VMAT-2; Fig. 4A-B). This suggests that the level of released GDNF in the SN or the striatum by the GDNF-transduced astrocytes was not sufficient to preserve the nigrostriatal fiber innervation.

In previous studies where viral vectors were used to overexpress GDNF in the striatum prior to an intrastriatal 6-OHDA lesion, GDNF was not only expressed in the striatum, but also anterogradely transported to the striatal output nuclei (i.e. GP, entopeduncular nucleus (EP) and SNpr (Kirik et al., 2000b; Georgievska et al., 2002a). In these areas, extensive aberrant sprouting of $\mathrm{TH}$-positive nigrostriatal fibers was 
observed and co-localized with the distribution of GDNF. In the present study, sprouting of TH-positive fibers was observed in the GP in some of the animals that received transplants of GDNF-expressing astrocytes into the striatum. In these animals, GDNF expressed from grafts placed most caudally in the striatum had diffused into the bordering GP and the sprouting of TH-positive fibers closely overlapped with the GDNF staining (Fig. 5A-C). No signs of sprouting were observed in the EP or SNpr following intranigral or intrastriatal transplantation of GDNF-transduced astrocytes. 


\section{Discussion}

In this study, rat-derived primary astrocytes were used for ex vivo gene delivery of GDNF in a rat model of Parkinson's disease. The in vitro genetically modified astrocytes were able to release GDNF in vivo, following transplantation into the striatum or SN. The GDNF expression was highest at 1 week after grafting ( $\sim 2.9$ in striatum, $\sim 0.2$ in $\mathrm{SN}, \mathrm{ng} / \mathrm{mg}$ tissue), reduced at 4 weeks ( $\sim 0.4$ in striatum, $\sim 0.06$ in $\mathrm{SN}$, $\mathrm{ng} / \mathrm{mg}$ tissue), however, was maintained at this lower level for up to at least 12 weeks ( $\sim .5 \mathrm{ng} / \mathrm{mg}$ tissue in striatum), the longest time-point studied. Furthermore, transplantation of GDNF-transduced astrocytes to the SN provided a significant protection of nigral TH-positive cells compared to control grafted animals, both after a mild $(7 \mu \mathrm{g})$ and a more severe $(21 \mu \mathrm{g})$ intrastriatal 6-OHDA lesion. However, when the GDNF-expressing cells were placed in the striatum, the released GDNF was not able to provide protection of the nigrostriatal fibers and, hence, the DA cell bodies in the SN.

\section{Long-term and local expression of GDNF in vivo}

We have in a previous study evaluated the potential of lentivirally transduced primary rat astrocytes for transgene expression (using GFP), both in vitro and in vivo following transplantation to the rat striatum (Ericson et al., 2002). Although $70-80 \%$ of the astrocytes expressed GFP in culture, only $1 \%$ of the grafted cells continued to express the transgene at 1 week after transplantation. This low fraction of GFP-expressing cells was confined to the graft core and co-localized with the expression of GFAP, as previously shown (Ericson et al., 2002). GFP-expression was maintained for at least 6 weeks, suggesting that the major down-regulation of the transgene expression occurred within the first week. Previous studies in transgenic animals expressing the lac $Z$ reporter gene have shown that the choice of CMV-promoter (mouse or human) affect 
the transgene expression in endogenous astrocytes (Fritschy et al., 1996; Aiba-Masago et al., 1999). When the human CMV-promoter was used, lacZ expression was only seen in activated glial cells (Fritschy et al., 1996), while lacZ expression from the mouse CMV-promoter was found in specifically in astrocytes independent on their state of activity (Aiba-Masago et al., 1999). In a separate study, Ridet et al. (2003) used a human CMV-promoter to drive GFP-expression in adult human astrocytes. Following transplantation to the mouse CNS, significant transgene expression was observed for up to 8 weeks, suggesting that the human CMV-promoter may be more efficient at maintaining transgene expression in human-derived astrocytes upon transplantation. In the present study, a human CMV-promoter was used to drive the transgene expression in rat-derived astrocytes, which may be an explanation why we have observed a down-regulation of the GDNF-expression following transplantation, where the GDNF tissue levels measured in the striatum were highest at 1 week $(\sim 2.9$ $\mathrm{ng} / \mathrm{mg}$ tissue) and reduced at 4 weeks to about $0.4 \mathrm{ng} / \mathrm{mg}$ tissue (16\% of the level at 1 week). This expression level was, however, maintained at 12 weeks post-grafting $(\sim 0.5$ ng/mg tissue), demonstrating a significant and stable GDNF overexpression between these two time-points. The level of GDNF expression from intranigral transplants was about 10 -fold lower than the level obtained in the striatum. This can be due to several reasons; 1) fewer cells were transplanted to the SN compared to striatum (200,000 vs. 300,000 ), although this would not account for the entire 10-fold difference, 2) cells transplanted to the midbrain may be less reactive and therefore express lower levels of GDNF or 3) differences in external signals from the host tissue (midbrain versus striatum) may affected the expression pattern of the transplanted astrocytes. In contrast, previous studies using various cell types (e.g. astrocytes, HiB5 cells and neurospheres) for ex vivo gene delivery of neurotrophic factors to the brain have not been able to 
demonstrate transgene expression in vivo for longer than 3-6 weeks posttransplantation (Martinez-Serrano et al., 1995; Yoshimoto et al., 1995; Cunningham \& Su, 2002; Johansen et al., 2002; Ostenfeld et al., 2002). In addition, the GDNF expression levels measured in this study were about 200-1000-fold higher than in the study by Cunningham \& Su, 2002), where they used retrovirally transduced primary mouse astrocytes for grafting to the mouse striatum. Taken together, our results suggest that lentivirally transduced primary astrocytes, in particular, are good candidate cells for ex vivo gene transfer in that they can provide a stable and long-term expression of GDNF in the rat brain.

Development of thymidine labeled cells revealed that the transplanted astrocytes had migrated away from the graft core both in the striatum and in the SN. However, immunohistochemistry and measurements of the GDNF tissue levels indicated that protein expression from the transplanted cells was only obtained at the site of transplantation and with no signs of retrograde or anterograde transport of the protein.

\section{Protective effects of GDNF}

The level of released GDNF from astrocytes transplanted into the SN was able to provide a near-complete protection of the nigral DA neurons in the $7 \mu \mathrm{g}$ 6-OHDA lesion model ( $80 \%$ vs. $40 \%$ of intact side in the control group). Even after the stronger $21 \mu \mathrm{g}$ lesion, intranigral transplantation of GDNF-transduced astrocytes was able to protect a significant number of $\mathrm{TH}-$ positive cells in the $\mathrm{SN}$, although to a lower extent ( $33 \%$ vs. $9 \%$ of intact side in the control group). By contrast, transplantation of GDNFexpressing astrocytes into the striatum, did not provide a protection of the striatal fibers and hence, the TH-positive cell bodies in the SNpc, despite high GDNF production in 
the striatum at the time of lesion (i.e. at 1 week post-transplantation). In fact, the level of GDNF released by the astrocytes in the striatum at 1 week $(2.93 \mathrm{ng} / \mathrm{mg}$ tissue $)$ was similar to, or even higher, than the levels obtained following direct injection of GDNFencoding LV or AAV vectors into the striatum (about $0.2-2 \mathrm{ng} / \mathrm{mg}$ tissue; Björklund et al., 2000; Kirik et al., 2000b; Georgievska et al., 2002a). In those studies, overexpression of GDNF prior to an intrastriatal 6-OHDA lesion efficiently protected both the nigrostriatal axon terminals and the DA neurons in the SN (Kirik et al., 2000a; Georgievska et al., 2002b). However, in contrast to the ex vivo gene transfer model, direct injection of LV or AAV vectors into the striatum leads to transduction of mainly striatal projection neurons, thus resulting in an anterograde transport of GDNF along the striatofugal pathway. As a consequence, GDNF is not only present in the striatum, but also at the cell soma level in the SN (Georgievska et al., 2002b). This may explain why viral vector-mediated delivery of GDNF to the striatum is so more efficient in protecting the nigral DA neurons than intrastriatal grafting of GDNF-expressing astrocytes, which limits the GDNF distribution to the site of transplantation.

It is evident from previous studies, using the intrastriatal 6-OHDA lesion model, that injections of recombinant GDNF protein to the SN alone provides good protection of the nigral DA cell bodies, but not the axon terminals, while delivery of GDNF to the striatum, i.e. at the site of toxin injection, protects the entire nigrostriatal DA system (Winkler et al., 1996; Kirik et al., 2000a; Rosenblad et al., 2000b). A preservation of the striatal DA innervation is necessary in order to obtain a functional recovery after an intrastriatal 6-OHDA lesion (Winkler et al., 1996; Kirik et al., 2000a). In the present study we did not observe a significant protection of the THpositive fiber terminals in the striatum, following either intranigral or intrastriatal grafting of GDNF-expressing astrocytes. As we have previously observed that long- 
term overexpression of GDNF in the striatum (using LV-vectors) can induce a downregulation of $\mathrm{TH}$ in the lesioned striatum, we also used VMAT-2, a DA marker which has been shown to be resistant to GDNF-induced down-regulation, to visualize and quantify the DA fiber terminals in the striatum (Georgievska et al., 2002a,2004). Since there was no significant difference in the VMAT-2-positive fiber density between the GDNF-transplanted animals and the control grafted groups, we can rule out a downregulation of $\mathrm{TH}$ in this study.

After testing the animals on amphetamine-induced rotational behavior at 3 weeks post-lesion, only the animals in the $7 \mu \mathrm{g}$ lesion group receiving GDNFtransduced astrocytes to the striatum demonstrated a significant difference from the control group. However, since we did not observe a significant anatomical protection in these animals, it is difficult to interpret the rotational behavior. All other groups failed to show any improvements in the amphetamine-induced rotation, including the animals that received intranigral transplants of GDNF-transduced astrocytes (7 and $21 \mu \mathrm{g}$ lesion groups) and that clearly had a significant protection of the nigral TH-positive cell bodies at 3 weeks after the lesion. However, since the TH-positive fiber terminals were not preserved in these animals it is unlikely that they would have shown behavioral improvements at later time-points.

Although direct injections of GDNF-encoding viral vectors to the striatum can provide efficient neuroprotection in the intrastriatal 6-OHDA lesion model, we have in previous studies observed unwanted side-effects, such as down-regulation of TH in the lesioned striatum and aberrant sprouting of $\mathrm{TH}$-positive fibers along the nigrostriatal pathway, due to anterograde transport of GDNF (Kirik et al., 2000b; Georgievska et al., 2002a). In this study, on the other hand, GDNF was only detected at the site of transplantation and marginal sprouting of TH-positive fibers was observed in the GP in 
a fraction of animals receiving intrastriatal grafts. This was due to some leakage of GDNF from the intrastriatal transplants into the neighboring GP, as confirmed by immunostaining for GDNF.

\section{Conclusions}

Transplantation of GDNF-transduced primary rat astrocytes to the striatum or SN of adult rats provided a long-term expression of GDNF. Although the level of expression reduced between 1 and 4 weeks, the expression was maintained for up to 12 weeks. Transplantation of GDNF-expressing astrocytes to the SN provided a significant protection of nigral TH-positive cells, demonstrating that lentivirally transduced rat astrocytes have good potential for neuroprotection in a rat model of PD. However, our findings suggest that in order to protect the nigral DA neurons, GDNF needs to be present at the level of the cell soma, at least using this mode of gene delivery (ex vivo). Thus, to achieve protection of both the DA cell bodies in the SNpc and the nigrostriatal fiber terminals, as well as behavioral improvements, it is most likely that GDNF needs to be delivered both to the $\mathrm{SN}$ and the striatum. This might be achieved by ex vivo gene transfer using astrocytes as cell vehicles. By delivering the cells at the site where GDNF can possess its functional effect and protect the cell bodies and axon terminals from dying, unwanted side effects, acquired as a consequence of anterograde transport when using direct injections of viral vectors, can be avoided. 


\section{Acknowledgement}

The authors would like to thank Ulla Jarl, AnnaKarin Oldén and Anneli Josefsson for excellent technical work, Bengt Mattsson for graphical input on the layout of the figures and Dr Deniz Kirik and Prof Anders Björklund for valuable scientific discussions. This study was supported by grants from the Swedish MRC (\#13479) and the Gene Therapy Program (\#13285).

\section{Abbreviations}

6-OHDA, 6-hydroxydopamine; DA, dopamine; GDNF, glial cell line-derived neurotrophic factor; GFP, green fluorescent protein; PD, Parkinson's disease; SN, substantia nigra; Str, striatum; TH, tyrosine hydroxylase; VMAT-2, vesicular monoamine transporter-2 


\section{References}

Aiba-Masago, S., Baba, S., Li, R.Y., Shinmura, Y., Kosugi, I., Arai, Y., Nishimura, M. \& Tsutsui, Y. (1999) Murine cytomegalovirus immediate-early promoter directs astrocyte-specific expression in transgenic mice. Am J Pathol, 154, 735-743.

Björklund, A., Kirik, D., Rosenblad, C., Georgievska, B., Lundberg, C. \& Mandel, R.J. (2000) Towards a neuroprotective gene therapy for Parkinson's disease: use of adenovirus, AAV and lentivirus vectors for gene transfer of GDNF to the nigrostriatal system in the rat Parkinson model. Brain Res, 886, 82-98.

Bohn, M.C., Choi-Lundberg, D.L., Davidson, B.L., Leranth, C., Kozlowski, D.A., Smith, J.C., O'Banion, M.K. \& Redmond, D.E., Jr. (1999) Adenovirusmediated transgene expression in nonhuman primate brain. Hum Gene Ther, 10, $1175-1184$.

Choi-Lundberg, D.L., Lin, Q., Chang, Y.N., Chiang, Y.L., Hay, C.M., Mohajeri, H., Davidson, B.L. \& Bohn, M.C. (1997) Dopaminergic neurons protected from degeneration by GDNF gene therapy. Science, 275, 838-841.

Cunningham, L.A. \& Su, C. (2002) Astrocyte delivery of glial cell line-derived neurotrophic factor in a mouse model of Parkinson's disease. Exp Neurol, 174, $230-242$

Deglon, N., Tseng, J.L., Bensadoun, J.C., Zurn, A.D., Arsenijevic, Y., Pereira de Almeida, L., Zufferey, R., Trono, D. \& Aebischer, P. (2000) Self-inactivating lentiviral vectors with enhanced transgene expression as potential gene transfer system in Parkinson's disease. Hum Gene Ther, 11, 179-190.

Duan, D., Yang, H., Zhang, J. \& Xu, Q. (2004) Long-term restoration of nigrostriatal system function by implanting GDNF genetically modified fibroblasts in a rat model of Parkinson's disease. Exp Brain Res. 
Duvoisin, R.C. (1992) Overview of Parkinson's disease. Ann N Y Acad Sci, 648, 187193.

Englund, U., Ericson, C., Rosenblad, C., Mandel, R.J., Trono, D., Wictorin, K. \& Lundberg, C. (2000) The use of a recombinant lentiviral vector for ex vivo gene transfer into the rat CNS. Neuroreport, 11, 3973-3977.

Ericson, C., Wictorin, K. \& Lundberg, C. (2002) Ex vivo and in vitro studies of transgene expression in rat astrocytes transduced with lentiviral vectors. Exp Neurol, 173, 22-30.

Fritschy, J.M., Brandner, S., Aguzzi, A., Koedood, M., Luscher, B. \& Mitchell, P.J. (1996) Brain cell type specificity and gliosis-induced activation of the human cytomegalovirus immediate-early promoter in transgenic mice. $J$ Neurosci, 16 , $2275-2282$.

Gash, D.M., Zhang, Z. \& Gerhardt, G. (1998) Neuroprotective and neurorestorative properties of GDNF. Ann Neurol, 44, S121-125.

Georgievska, B., Kirik, D. \& Björklund, A. (2002a) Aberrant sprouting and downregulation of tyrosine hydroxylase in lesioned nigrostriatal dopamine neurons induced by long-lasting overexpression of glial cell line derived neurotrophic factor in the striatum by lentiviral gene transfer. Exp Neurol, 177, 461-474.

Georgievska, B., Kirik, D. \& Björklund, A. (2004) Overexpression of glial cell linederived neurotrophic factor using a lentiviral vector induces time- and dosedependent downregulation of tyrosine hydroxylase in the intact nigrostriatal dopamine system. J Neurosci, 24, 6437-6445. 
Georgievska, B., Kirik, D., Rosenblad, C., Lundberg, C. \& Björklund, A. (2002b)

Neuroprotection in the rat Parkinson model by intrastriatal GDNF gene transfer using a lentiviral vector. Neuroreport, 13, 75-82.

Johansen, J., Rosenblad, C., Andsberg, K., Møller, A., Lundberg, C., Björklund, A. \& Johansen, T.E. (2002) Evaluation of Tet-on system to avoid transgene downregulation in ex vivo gene transfer to the CNS. Gene Ther, 9, 1291-1301.

Kirik, D., Georgievska, B. \& Björklund, A. (2004) Localized striatal delivery of GDNF as a treatment for Parkinson disease. Nat Neurosci, 7, 105-110.

Kirik, D., Rosenblad, C. \& Björklund, A. (2000a) Preservation of a functional nigrostriatal dopamine pathway by GDNF in the intrastriatal 6-OHDA lesion model depends on the site of administration of the trophic factor. Eur $J$ Neurosci, 12, 3871-3882.

Kirik, D., Rosenblad, C., Björklund, A. \& Mandel, R.J. (2000b) Long-term rAAVmediated gene transfer of GDNF in the rat Parkinson's model: intrastriatal but not intranigral transduction promotes functional regeneration in the lesioned nigrostriatal system. $J$ Neurosci, 20, 4686-4700.

Kordower, J.H., Emborg, M.E., Bloch, J., Ma, S.Y., Chu, Y., Leventhal, L., McBride, J., Chen, E.Y., Palfi, S., Roitberg, B.Z., Brown, W.D., Holden, J.E., Pyzalski, R., Taylor, M.D., Carvey, P., Ling, Z., Trono, D., Hantraye, P., Déglon, N. \& Aebischer, P. (2000) Neurodegeneration prevented by lentiviral vector delivery of GDNF in primate models of Parkinson's disease. Science, 290, 767-773.

Lapchak, P.A., Jiao, S., Collins, F. \& Miller, P.J. (1997) Glial cell line-derived neurotrophic factor: distribution and pharmacology in the rat following a bolus intraventricular injection. Brain Res, 747, 92-102. 
Lin, L.F., Doherty, D.H., Lile, J.D., Bektesh, S. \& Collins, F. (1993) GDNF: a glial cell line-derived neurotrophic factor for midbrain dopaminergic neurons. Science, $260,1130-1132$.

Lundberg, C. (1999) Engineered cells and ex vivo gene transfer. In Dunnett, S.B. (ed.) Neural Transplantation Methods. Humana Press, Totowa, NJ, pp. 89-102.

Mandel, R.J. (2000) Effect of acute L-Dopa pretreatment on apomorphine-induced rotational behavior in a rat model of Parkinson's disease. Exp Neurol, 161, 212219.

Mandel, R.J., Spratt, S.K., Snyder, R.O. \& Leff, S.E. (1997) Midbrain injection of recombinant adeno-associated virus encoding rat glial cell line-derived neurotrophic factor protects nigral neurons in a progressive 6hydroxydopamine-induced degeneration model of Parkinson's disease in rats. Proc Natl Acad Sci U S A, 94, 14083-14088.

Martinez-Serrano, A., Lundberg, C., Horellou, P., Fischer, W., Bentlage, C., Campbell, K., McKay, R.D., Mallet, J. \& Björklund, A. (1995) CNS-derived neural progenitor cells for gene transfer of nerve growth factor to the adult rat brain: complete rescue of axotomized cholinergic neurons after transplantation into the septum. J Neurosci, 15, 5668-5680.

McCown, T.J., Xiao, X., Li, J., Breese, G.R. \& Samulski, R.J. (1996) Differential and persistent expression patterns of CNS gene transfer by an adeno-associated virus (AAV) vector. Brain Res, 713, 99-107.

Olsson, M., Campbell, K., Wictorin, K. \& Björklund, A. (1995) Projection neurons in fetal striatal transplants are predominantly derived from the lateral ganglionic eminence. Neuroscience, 69, 1169-1182. 
Ostenfeld, T., Tai, Y.T., Martin, P., Déglon, N., Aebischer, P. \& Svendsen, C.N. (2002) Neurospheres modified to produce glial cell line-derived neurotrophic factor increase the survival of transplanted dopamine neurons. J Neurosci Res, 69, 955-965.

Paxinos, G. \& Watson, C. (1986) The Rat Brain in Stereotaxic Coordinates. Academic Press, San Diego.

Perez-Navarro, E., Arenas, E., Marco, S. \& Alberch, J. (1999) Intrastriatal grafting of a GDNF-producing cell line protects striatonigral neurons from quinolinic acid excitotoxicity in vivo. Eur J Neurosci, 11, 241-249.

Ridet, J.L., Sarkis, C., Serguera, C., Zennou, V., Charneau, P. \& Mallet, J. (2003) Transplantation of human adult astrocytes: efficiency and safety requirements for an autologous gene therapy. J Neurosci Res, 72, 704-708.

Rosenblad, C., Grønborg, M., Hansen, C., Blom, N., Meyer, M., Johansen, J., Dago, L., Kirik, D., Patel, U.A., Lundberg, C., Trono, D., Björklund, A. \& Johansen, T.E. (2000a) In vivo protection of nigral dopamine neurons by lentiviral gene transfer of the novel GDNF-family member neublastin/artemin. Mol Cell Neurosci, 15, 199-214.

Rosenblad, C., Kirik, D. \& Björklund, A. (2000b) Sequential administration of GDNF into the substantia nigra and striatum promotes dopamine neuron survival and axonal sprouting but not striatal reinnervation or functional recovery in the partial 6-OHDA lesion model. Exp Neurol, 161, 503-516.

von Schwedler, U., Song, J., Aiken, C. \& Trono, D. (1993) Vif is crucial for human immunodeficiency virus type 1 proviral DNA synthesis in infected cells. $J$ Virol, 67, 4945-4955. 
West, M.J. (1999) Stereological methods for estimating the total number of neurons and synapses: issues of precision and bias. Trends Neurosci, 22, 51-61.

Winkler, C., Sauer, H., Lee, C.S. \& Björklund, A. (1996) Short-term GDNF treatment provides long-term rescue of lesioned nigral dopaminergic neurons in a rat model of Parkinson's disease. J Neurosci, 16, 7206-7215.

Yoshimoto, Y., Lin, Q., Collier, T.J., Frim, D.M., Breakefield, X.O. \& Bohn, M.C. (1995) Astrocytes retrovirally transduced with BDNF elicit behavioral improvement in a rat model of Parkinson's disease. Brain Res, 691, 25-36.

Zufferey, R., Dull, T., Mandel, R.J., Bukovsky, A., Quiroz, D., Naldini, L. \& Trono, D. (1998) Self-inactivating lentivirus vector for safe and efficient in vivo gene delivery. J Virol, 72, 9873-9880.

Zufferey, R., Nagy, D., Mandel, R.J., Naldini, L. \& Trono, D. (1997) Multiply attenuated lentiviral vector achieves efficient gene delivery in vivo. Nat Biotechnol, 15, 871-875. 


\section{Figure legends}

\section{Figure 1}

Biochemical and behavioral analyses at different time-points following transplantation of GFP- or GDNF-transduced primary astrocytes into intact animals. (A-B) GDNF tissue levels (ng/mg tissue) in the SN or Str as determined by ELISA. (A) At one week after transplantation the level of GDNF measured in the SN was $0.196 \pm 0.053 \mathrm{ng} / \mathrm{mg}$ tissue, which was significantly higher from the control group $(P<0.0001)$. At 4 weeks the GDNF level had decreased to $0.057 \pm 0.014 \mathrm{ng} / \mathrm{mg}$ tissue, however, remained significantly elevated compared to the control group $(P<0.05)$. (B) The GDNF tissue level in the Str at 1 week post-grafting was $2.93 \pm 0.28 \mathrm{ng} / \mathrm{mg}$ tissue, which was significantly higher than the control group, as well as later time-points $(P<0.0001)$. The GDNF tissue levels decreased at the later time-points (4 and 12 weeks), however, remained significantly higher than the control group ( $4 \mathrm{w}, 0.42 \pm 0.12 \mathrm{ng} / \mathrm{mg}$ tissue; 12 $\mathrm{w}, 0.53 \pm 0.068 \mathrm{ng} / \mathrm{mg}$ tissue; $P<0.01$ ). (C) Injections of amphetamine induced a significant contralateral turning at 1 week $(5.39 \pm 1.19$ turns/min; $P<0.001)$ following transplantation of GDNF-transduced astrocytes into the striatum compared to control animals receiving GFP-transduced astrocytes. (D) As the level of GDNF in the tissue decreased over time, the turning rate in the amphetamine rotation was also reduced (C) and a significant correlation between the turning rate and the striatal GDNF tissue levels was observed $(R=0.825 ; \quad P<0.0001)$. The data in $\mathrm{A}-\mathrm{C}$ are presented as mean \pm S.E.M. The control group represents an average of animals receiving grafts of GFP-expressing astrocytes, and the non-injected contralateral side of animals receiving GDNF-transduced astrocytes. * Significantly different from control group. $\dagger$ Significantly different from other GDNF groups. \# Significantly different from the 12 weeks group. 


\section{Figure 2}

Immunohistochemical visualization of transgene expression in intact animals at 1 and 4 weeks following transplantation of GFP- and GDNF-transduced primary astrocytes. (A-B) Distribution of GFP and GDNF at 4 weeks after transplantation into the SN. (CD) GFP-expressing astrocytes in the striatum at 1 and 4 weeks post-transplantation were only found in the graft core. (E-F) Distribution of secreted GDNF from the transplanted cells at 1 and 4 weeks after transplantation. The level of released GDNF at 1 week (about $2.93 \mathrm{ng} / \mathrm{mg}$ tissue) resulted in a widespread distribution of GDNF in the striatum, whereas the GDNF expression at 4 weeks (about $0.42 \mathrm{ng} / \mathrm{mg}$ tissue) was confined to a smaller area in the striatum. Arrowheads in E and F indicate the area of GDNF expression. cc, corpus callosum; cp, cerebellar peduncle; lv, lateral ventricle; SNpc, substantia nigra pars compacta; SNpr, substantia nigra pars reticulata; Str, striatum. Scale bars represent $200 \mu \mathrm{m}$.

\section{Figure 3}

Representative photomicrographs of coronal sections through the midbrain immunostained for TH, from the following groups: (A) Intact SN. (B) GFP-transduced astrocytes transplanted to the $\mathrm{SN}$ in a $7 \mu \mathrm{g}$ 6-OHDA lesion. (C) GFP-transduced astrocytes transplanted to the SN in a $21 \mu \mathrm{g}$ lesion. (E) GDNF-transduced astrocytes transplanted to the $\mathrm{SN}$ in a $7 \mu \mathrm{g}$ lesion. (F) GDNF-transduced astrocytes transplanted to the $\mathrm{SN}$ in a $21 \mu \mathrm{g}$ lesion. $(\mathrm{H})$ GDNF-transduced astrocytes transplanted to the $\mathrm{Str}$ in a $7 \mu$ g lesion. (I) GDNF-transduced astrocytes transplanted to the Str in a $21 \mu \mathrm{g}$ lesion. The number of TH-positive cells in the nigra after transplantation of GFP- or GDNFtransduced astrocytes to the SN (D) or the Str (G) was estimated using stereology and 
expressed as percentage of intact side. Quantification of TH-positive cells at 3 weeks post-lesion showed a significant protection of nigral DA neurons when GDNFexpressing cells were transplanted into the $\mathrm{SN}$ in both lesion models compared to GFPtreated groups, whereas no significant cell protection was seen when GDNF-transduced cells were transplanted into the Str $(G)$. cp, cerebellar peduncle; SNpc, substantia nigra pars compacta; SNpr, substantia nigra pars reticulata. Data are presented as mean \pm S.E.M. *Significantly different from the GFP-transplanted control groups $(P<0.05)$. Scale bar represents $300 \mu \mathrm{m}$.

\section{Figure 4}

Quantification of TH (A) and VMAT-2 (B) positive fiber densities in the striatum at 3 weeks after the 6-OHDA lesion. The TH- and VMAT-2-positive striatal fiber densities were similar between the different treatment groups and no significant protection was observed in the GDNF-treated groups, irrespective of lesion model. Data are presented as mean \pm S.E.M.

\section{Figure 5}

Photomicrographs of adjacent sections covering the globus pallidus (GP) and caudal striatum at 3 weeks after lesion, immunostained for TH and GDNF. (A) Intact side with normal preterminal nigrostriatal fibers passing through the GP and terminating in the striatum. In animals receiving GDNF-transduced astrocytes, diffusion of GDNF into the GP from the most caudally placed graft was observed (B). Sprouting of TH-positive fibers was detected in the same area as the GDNF expression, indicated with arrows (C). cc, corpus callosum; GP, globus pallidus; lv, lateral ventricle; Str, striatum. Scale 
bar represents $300 \mu \mathrm{m} . *$ Adjacent sections as demonstrating by the appearance of the same blood vessels. 